\title{
Cryptophthalmos: a report on three sibling cases
}

\author{
ZHANG HANCHENG \\ From the Department of Ophthalmology, South-Western Hospital, Chongqing, China
}

SUMmaRY Three siblings, two females and one male, with the rare disease, cryptophthalmos, are reported on. Cryptophthalmos is usually familiar, inherited as an autosomal recessive trait. The clinical manifestations indicate that the eyeball is present but disorganised; the lid muscles, extraocular muscles, and the nerve elements controlling ocular movements in the brain are developed. Treatment is of no avail, but in unilateral cases the partial lid coloboma, anterior symblepharon, and corneal opacification of the opposite eye may be somewhat improved by surgery.

Cryptophalmos is a rare congenital anomaly characterised by an uninterrupted continuity of the skin of the forehead with that of the cheek, resulting in total ablepharon. It was first reported in 1872 by Zehender and Manz, ${ }^{1}$ and only two cases have been presented in China. ${ }^{23} \mathrm{~A}$ family is now reported here in which three of the five siblings were affected (Fig. $1,2)$.

\section{Case report}

Case $1\left(\mathrm{III}_{1}\right)$ was the first child of the family, born at term in 1949, and was seen on 30 May 1982 for bilateral congenital absence of palpebrae. During pregnancy her mother, except for malnutrition, had no history of noticeable illness, trauma, or exposure to toxic agents or radiation. At the age of 3 months the baby was admitted to hospital and the skin overlying her orbits incised, but no corneas were found.

Correspondence to Dr Zhang Hancheng.
At 33 years old the patient looked pale, was fat, was $128 \mathrm{~cm}$ in height, and had normal neuropsychological development and average intellect (Fig. 3). The upper and lower limbs measured $57 \mathrm{~cm}$ and $67 \mathrm{~cm}$ in length respectively. Both legs were bowed leftwards. An unusual growth of hairs extending from the temples forwards and downwards to both sides of the forehead made the haired areas appear triangular in shape. The eyebrows were almost absent; only a few remnants were visible near the root of the nose.

On the skin covering the orbit there was a horizontal shallow groove, 3 by $0.2 \mathrm{~cm}$. A domed prominence about the size of a pea in the centre of the orbit indicated the undeveloped eyeball. A sudden sound elicited a reflex wrinkling of the orbital skin, but exposure to strong light failed to evoke a similar response. Voluntary and conjugate movements of both occult globes could be perceived. No lashes or lid structures, including tarsi, were found. The karyotype showed nothing remarkable.

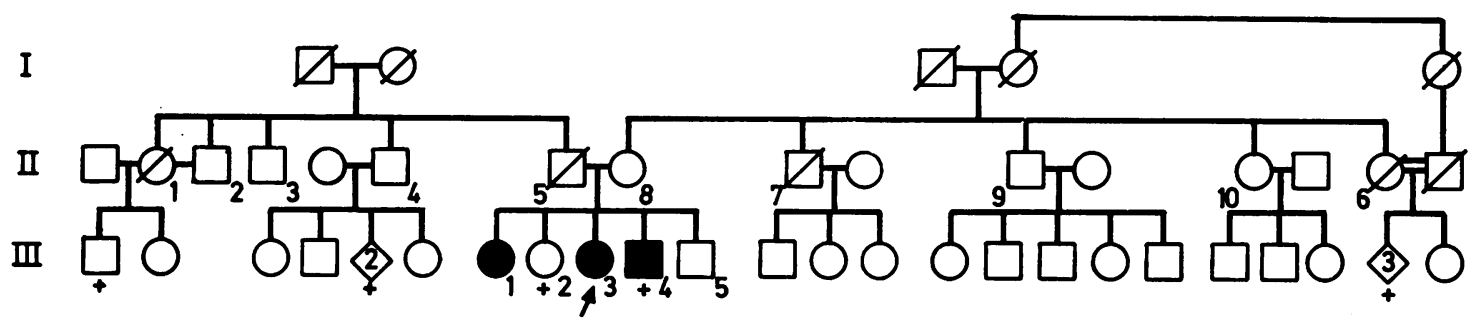

Fig. 1 Pedigree of the propositus (arrow) and his family. III $I_{1-5}$ : full-term delivery. III $_{2}$ : born in 1952, died at 5 months. III : $^{\circ}$ born in 1956. $11_{5}$ : 58 years old, died at 1982. $11_{8}: 49$ years old. 


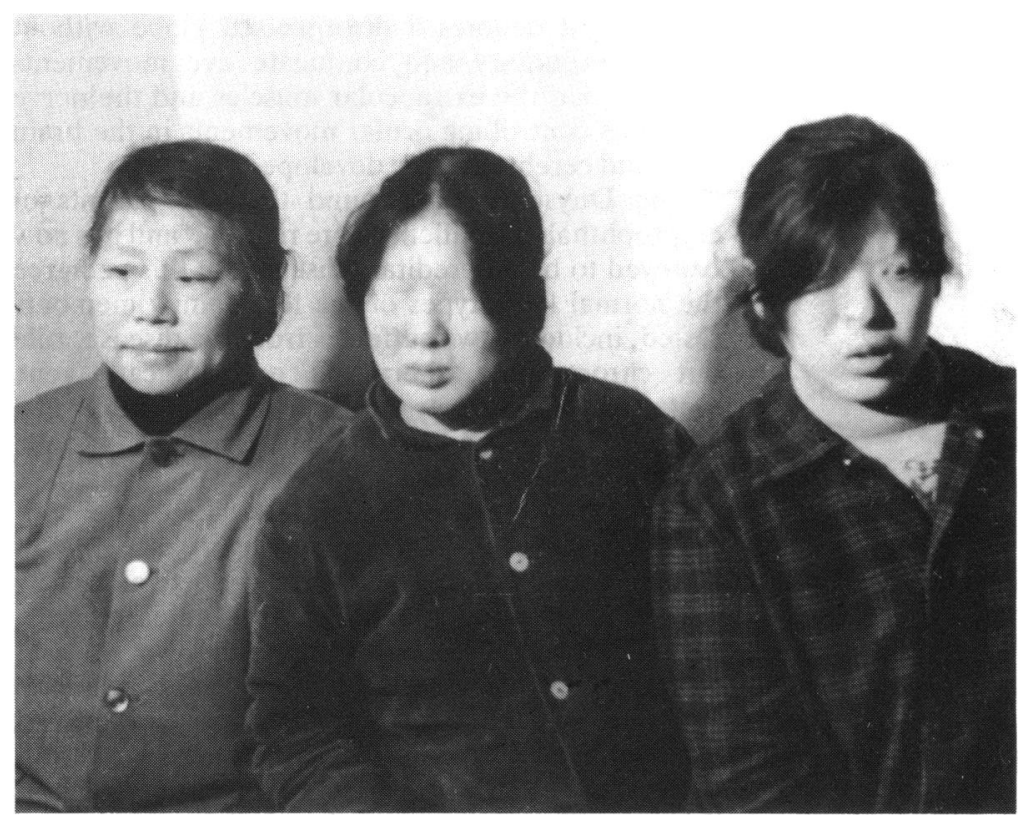

Fig. 2 From left to right: $I I_{8}, I I I_{I}$, and $\mathrm{III}_{3}$.

Case $2\left(\mathrm{III}_{3}\right)$ was born with right cryptophthalmos in 1953. Poor vision of the left eye necessitated optical iridectomy five years ago (Fig. 4). On physical examination the pattern of hair growth and the appearance of the right side of the face were similar

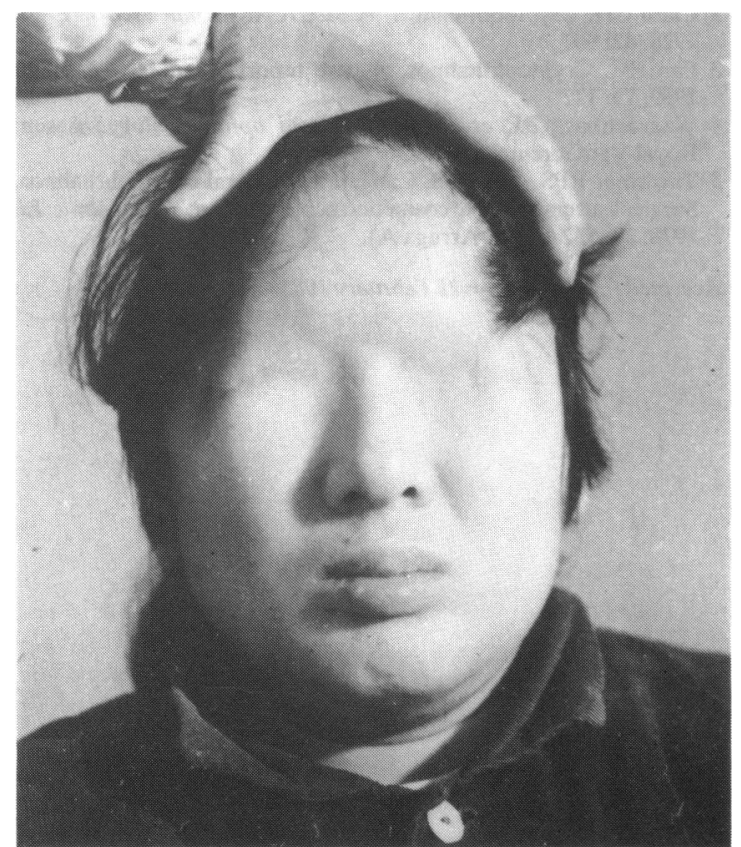

Fig. 3 III, bilateral cryptophthalmos. to those of case 1 . In the left eye she had: vision $0 \cdot 06$; coloboma of the medial two-thirds of the upper lid (Fig. 5), which had no lashes and was adherent to the cornea, which showed scattered opacifications; an anterior chamber slightly deeper than normal; the

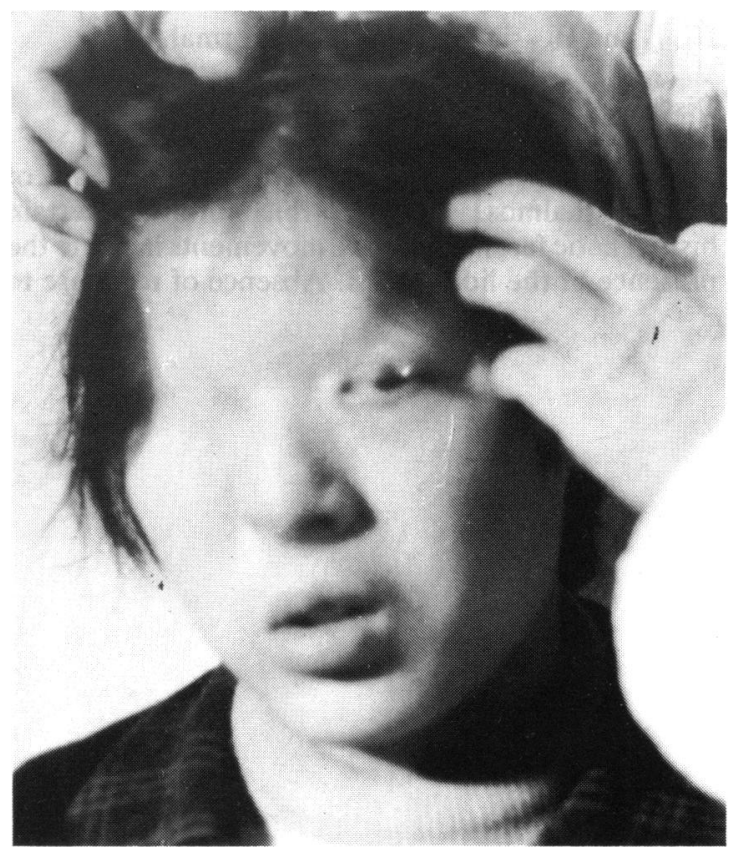

Fig. 4 III , right cryptophthalmos. 


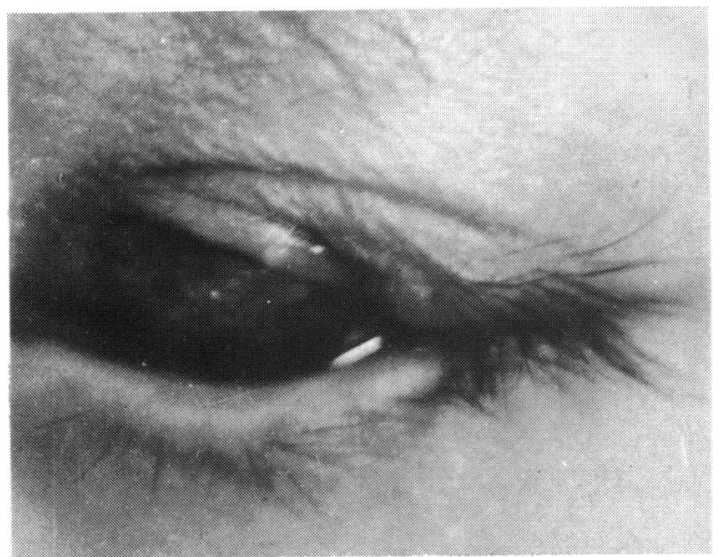

Fig. 5 Left eye of $\mathrm{III}_{3}$, showing coloboma of medial twothirds of the upper lid, which is adherent to the cornea.

outer part of the brownish iris lacking; the pupil large and reactive; the lens clear; the fundus invisible; the intraocular pressure normal on palpation. The karyotype was normal.

Case 3 ( $\left.\mathrm{III}_{4}\right)$ was born in 1954 with a facial appearance identical with that of case 1 . He lived only 2 months.

No other family members were affected. Their parents were not consanguinous and had no congenital abnormalities. The father died of cerebral haemorrhage during the final follow-up of the family in 1982. Palm and finger prints and the karyotypes of III $_{1,3,5}$ and $\mathrm{II}_{5,8}$ showed nothing abnormal.

\section{Discussion}

These three cases have the typical symptoms of cryptophthalmos, some of which indicate certain histogenetic facts. Blink-like movements indicate the presence of the lid muscles. Absence of response to strong light denotes a disorganised globe without vision. Voluntary and conjugate eye movements indicate that the extraocular muscles and the nerve elements controlling ocular movements in the brain stem and cerebrum have developed.

Van Duyse in 1889 found that the parents of cryptophthalmos patients were related, ${ }^{4}$ and it is now believed to be a hereditary disease. In this pedigree the normal karyotypes of the four family members tested, including two sufferers from the disease, rule out chromosome aberration and indicate gene mutation. The family history suggests autosomal recessive transmission of the trait, as has usually been reported.

Because the eye is disorganised and the conjunctival sac is usually absent, recovery of sight and reconstruction of the lid and conjunctival sac by plastic surgery are impossible. ${ }^{25}$ In a unilateral case, with malformations of the opposite eye such as partial lid coloboma, anterior symblepharon, and cornea opacifications, the vision and facial appearance can be improved only partially by operation, because developmental abnormalities, especially of the posterior segment, are almost always present to certain degree, rendering complete recovery impossible.

\section{References}

1 Duke-Elder WS. System of ophthalmology. London, Kimpton, 1964: 3: 827-33.

2 Chou CH. Cryptophthalmos. A case report. Chin Med J (Engl) 1928; 42: 907.

3 Fan HC. Cryptophthalmos. A case report. Chin Med J (Engl) 1959; 79: 172.

4 Waardenburg PJ, et al. Genetics and ophthalmology. Assen: Royal VanGorcum, 1961: 236.

5 Tavermer RPS, Vaya BS. Congenital bilateral cryptophthalmos. Surgical attempt for a cosmetic reconstruction. Ophthalmic Lit 1978; 32: 532 (abstr, Arruga A).

Accepted for publication 21 February 1985. 